\title{
Even non-experts identify non-dysplastic lesions in inflammatory bowel disease via chromoendoscopy: results of a screening program in real-life
}

(ㄷ)(1) $(9)$

\author{
Authors \\ disease of Castilla y León)

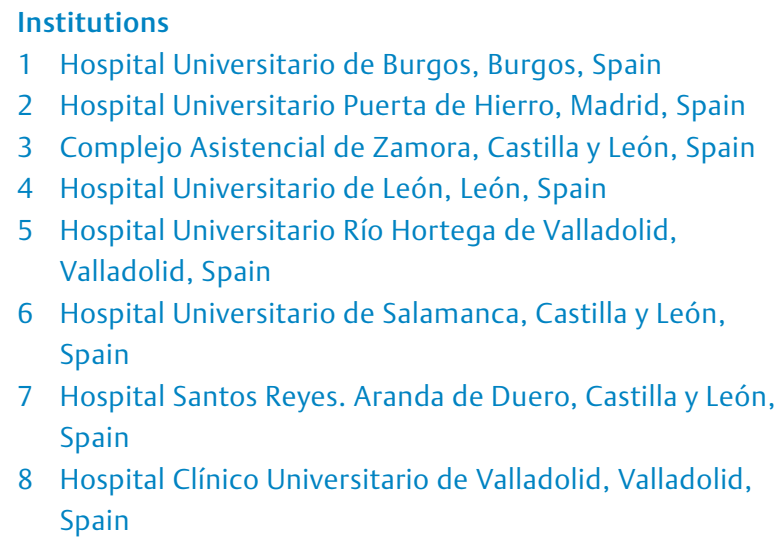

Beatriz Sicilia Aladrén ${ }^{1}$, Yago González-Lama², María García-Alvarado³ ${ }^{\text {, Mónica Sierra }}{ }^{4}$, Jésus Andrés Barrio ${ }^{5}$, Vanesa Prieto Vicente ${ }^{6}$, Luis Hernández ${ }^{7}$, Benito Velayos ${ }^{8}$, Lara Arias Garcia ${ }^{1}$, Lucia Relea ${ }^{2}$, Patricia Suarez ${ }^{4}$, Ramón Atienza ${ }^{5}$, Mónica Vásquez ${ }^{7}$, Luis Fernández-Salazar ${ }^{8}$, Fernando Muñoz ${ }^{6}$, on behalf of GEICYL (group of inflammatory bowel

submitted 7.7.2018

accepted after revision 2.1.2019

Bibliography

DOI https://doi.org/10.1055/a-0839-4514 |

Endoscopy International Open 2019; 07: E743-E750

(c) Georg Thieme Verlag KG Stuttgart · New York eISSN 2196-9736

Corresponding author

Beatriz Sicilia, MD, PhD, IBD Unit Cooordinator;

Gastroenterology and Hepatology Department, Hospital

Universitario de Burgos, Av Islas Baelares s/n 09006, Burgos

947281800 , Spain

bsicilia4@gmail.com

\section{ABSTRACT}

Background and study aims Chromoendoscopy with targeted biopsy is the technique of choice for colorectal cancer screening in longstanding inflammatory bowel disease. We aimed to analyze results of a chromoendoscopy screening program and to assess the possibility of identifying lowrisk dysplastic lesions by their endoscopic appearance in order to avoid histological analysis.

Materials and methods We retrospectively reviewed chromoendoscopies performed between February 2011 and June 2017 in seven Spanish hospitals in a standardized fashion. We analyzed the findings and the diagnostic yield of the Kudo pit pattern for predicting dysplasia.

Results A total of 709 chromoendoscopies (569 patients) were reviewed. Median duration of disease was 16.7 years (SD 8.1); $80.4 \%$ had ulcerative colitis. A total of 2025 lesions (3.56 lesions per patient) were found; two hundred and thirty-two lesions were neoplastic (11.5\%) (223 were LGD (96.1\%), eight were HGD (3.4\%), and one was colorectal cancer $(0.5 \%)$. The correlation between dysplasia and Kudo pit patterns predictors of dysplasia ( $\geq$ III) was low, with an area under the curve of 0.649. Kudo I and II lesions were correctly identified with a high negative predictive value ( $92 \%)$, even by non-experts. Endoscopic activity, Paris 0 -Is classification, and right colon localization were risk factors for dysplasia detection, while rectum or sigmoid localization were protective against dysplasia.

Conclusions Chromoendoscopy in the real-life setting detected $11 \%$ of dysplastic lesions with a low correlation with Kudo pit pattern. A high negative predictive value would prevent Kudo I and, probably, Kudo II biopsies in the left colon, reducing procedure time and avoiding complications.

\section{Introduction}

Patients with longstanding inflammatory bowel disease (IBD), extensive or left ulcerative colitis, or more than one-third colonic-extension Crohn's disease (CD), have an increased risk for colorectal cancer (CRC) [1,2], and surveillance colonoscopy is recommended to detect dysplasia. Stenosis or previous dysplastic lesions, extensive ulcerative colitis with severe activity, pseudopolyps, first-degree CRC diagnosed before age 50 years, 
and primary sclerosing cholangitis are the most important risk factors for CRC [3]. No randomized clinical trials have analyzed if surveillance is effective in this scenario, although some case series suggest such a possibility, like those included in a 2003 review [4], in which the 5-year survival of cancer diagnosed within surveillance was significantly higher than that diagnosed outside surveillance. However, as a recent Cochrane review indicates [5], although there is no clear evidence regarding improved survival, diagnosis of CRC at an earlier stage has a better prognosis.

The SCENIC consensus [6] reinforces the place of chromoendoscopy as the preferred technique for surveillance of dysplasia in IBD patients, including a meta-analysis which concluded that chromoendoscopy detected a significantly greater proportion of patients with dysplasia (relative risk 1.8; $95 \%$ confidence interval $[\mathrm{Cl} 1.2-2.6])$, with an absolute increase of $6 \%(95 \% \mathrm{Cl}$ 3-9\%) more patients. Thus, evidence regarding chromoendoscopy in this scenario is clear but implementation of chromoendoscopy in different hospitals is challenging, mostly because of the need for systematic training, partnered learning in describing morphology and Kudo pit-pattern, and increased time for the procedure.

Chromoendoscopy involves application of dye to the colonic mucosa to highlight the architecture pooling of dye in the grooves between the colonic crypts and within the colonic pits and polyp ridges. The widely accepted Kudo pit pattern classification [7] is used to differentiate five types of staining patterns to predict neoplastic lesions with high percentages of sensitivity, specificity, and positive and negative predictive values. A recent Spanish real-life study [8] reported a high accuracy with optical diagnosis using the Kudo pit pattern to improve management of these lesions. Our study aimed to analyze results of a chromoendoscopy screening program in seven hospitals in Spain and to assess the possibility of identifying low-risk dysplastic lesions by their endoscopic appearance to avoid histological analysis. We also sought to identify factors associated with dysplasia development.

\section{Materials and methods}

We retrospectively collected consecutive screening colonoscopies via chromoendoscopy performed between February 2011 and June 2017 for patients with longstanding IBD in seven different Spanish hospitals. Inclusion criteria were as follows: left or extensive ulcerative colitis and CD involving more than onethird of the colonic mucosa, more than 8 years' disease duration, and clinical remission (partial Mayo score less than 3 for ulcerative colitis or Harvey Bradshaw < 5 for (RC). Patients had signed informant consent allowing the use of their clinical information for research purposes.

We included demographic characteristics of patients such as sex and age and clinical disease characteristics such as years of disease duration and colonic extension in our database.

Following the Boston Bowel Preparation Scale [9], each endoscopists graded the quality of bowel cleansing. Adequate preparation was defined as a total score $\geq 6$ with no segments $<2$, excluding procedures with inadequate quality. Based on the Mayo Endoscopy Subscore for ulcerative colitis [10] and Simplified Endoscopic activity Score for CD (SES-CD) [11], the endoscopists recorded endoscopic disease activity, excluding patients with moderate or severe endoscopic activity (Mayo $>2$ or SES-CD $>5$ )

The chromoendoscopy procedure was performed with indigo carmine $(0.2-0.4 \%)$ or methylene blue managed with a catheter spray and high-definition endoscopes, including both tertiary referral centers and local community hospitals, according to the SURFACE guidelines [12] and recording the time for the whole procedure. All the endoscopists started to perform chromoendoscopy after systematic training regarding a standardized operating procedure and partnered learning as recommended [13]. In all the hospitals, high-definition endoscopes were used with digital magnification but without optical magnification (Olympus Evis Exera II Cv-180 and Evis Exera III Cv190).

During chromoendoscopy, mucosal healing was described according to each colonic segment and presence or absence of pseudopolyps. Macroscopic characterization of the lesions was based on size and location, Kudo pit pattern, and morphologic characteristics according to the SCENIC consensus-modified Paris classification, excising all visible lesions with biopsy forceps or taking samples of perilesional mucosa with a polypectomy snare to rule out surrounding dysplasia.

Histology was used as the gold standard processing sample, using standard methods. Histologic evaluations were performed by expert gastrointestinal pathologists. If dysplasia was noted, a second pathologist validated the result. Neoplastic lesions were classified according to the Vienna classification into low-grade dysplasia (LGD), high-grade dysplasia (HGD), or CRC.

Statistical analysis was performed using SPSS V.20.0 (IBM, Somers, New York, United States). Quantitative variables are expressed as means and SDs. Categorical variables are expressed as total number and frequencies (\%). Quantitative variables were analyzed using the Student's t-test, and qualitative variables were analyzed using the $\mathrm{X} 2$ test. Univariate binary logistic regression was performed to select variables associated with presence of dysplasia. For multivariable logistic regression analyses, only candidate variables with $P$ values $\leq 0.05$ on univariate analysis were included in the final multivariate model. We included odds ratios (ORs) with $95 \%$ Cls to quantify the magnitude of the association. Diagnosis accuracy and Cls for all features were derived from $2 \times 2$ tables. Outcome parameters were sensitivity, specificity, positive predictive value (PPV), negative predictive value (NPV), and overall accuracy.

\section{Results}

During the inclusion period, 719 chromoendoscopies were performed though 10 (1.3\%) were excluded due to severe endoscopic activity (1.3\%) despite patients being clinically in remission. We finally included 709 consecutive chromoendoscopies (569 patients, $45.7 \%$ women) for screening for CRC in a population with longstanding IBD. None of the patients had previous dysplastic lesion or past history of CRC ( $\triangleright$ Fig. 1). Median dura- 


\begin{tabular}{l}
$\begin{array}{l}\text { Consecutive chromoendoscopies 2011-2017 } \\
\mathrm{n}=719\end{array}$ \\
\hline $\begin{array}{l}\text { Excluded: } \\
\text { Endoscopic activity } \mathrm{n}=10\end{array}$ \\
Total included $\mathrm{n}=709$ \\
Available data for analysis: $100 \%$ \\
- Disease location \\
- Morphology and lesion location \\
- Histological findings
\end{tabular}

- Fig. 1 Study flowchart.

tion of disease was 16.7 years (SD 8.1); $80.4 \%$ of lesions $(n=$ $458)$ were ulcerative colitis (46.6\% extensive), $17.9 \%(n=102)$ were $C D$, and $1.6 \%(n=9)$ were indeterminate colitis. Mean duration of colonoscopy was $23.6 \pm 19.77$ minutes. Despite clinical remission, endoscopic activity was observed in $12.1 \%$ of our patients, with a mucosal healing of $87.9 \%$ (21.5\% Mayo 1 and $66.4 \%$ Mayo 2). Adequate bowel preparation based on Boston Bowel Preparation Scale was present in $93.5 \%$ of patients. A total of 429 patients underwent only one chromoendoscopy, while 140 patients underwent more than one chromoendoscopy during the study period. Demographic characteristics of the patients are shown in $>$ Table 1 .

We identified 2025 lesions (3.56 lesions per patient, 2.86 lesions per chromoendoscopy) and most of them were located proximal to the splenic flexure (76\%), including the rectum (16.7\%), sigmoid colon (27.7\%), or left colon (31.4\%); $24 \%$ of the lesions were localized in the proximal colon, either in the transverse $(10.9 \%)$ or right $(13.3 \%)$ colon. Endoscopic characteristics are shown in $>$ Table 2 . Lesions with dysplasia corresponded to 151 different patients, implying that $26.5 \%$ of the patients analyzed had dysplastic lesions (1 or more lesion with dysplasia). The number of dysplastic lesions per patient was 0.4 .

A total of 1793 (88.5\%) lesions were non-neoplastic and histological analysis comprised normal mucosa (43.9\%), hyperplastic lesions (36\%), inflammatory lesions (13.1\%), or other (7\%). Two hundred and thirty-two lesions (11.5\%) were neoplastic and among these, 223 were LGD (96.1\%), 8 were HGD $(3.4 \%)$, and $1(0.5 \%)$ was CRC ( Table 3$)$.

Five of the 8 HGD lesions (62.5\%) were localized in proximal colon (right or transverse colon) and $75 \%$ (6/8) were sessile polyps with a Paris classification of 0 -Is or 0 -Isp, with just two superficial elevated lesions (Paris Ila). All HGD lesions were completely removed. One invasive CRC was observed in the rectum of a male patient with left ulcerative colitis of 18 years' duration. This lesion was a depressed $1-\mathrm{cm}$ lesion (Paris 0 -IIc), with a Kudo $\mathrm{V}$ pit pattern. The patient underwent total colect-
- Table 1 Baseline patient demographics and disease characteristics.

\begin{tabular}{|l|c|}
\hline Total number of patients included & 569 \\
\hline Total colonoscopies & 709 \\
\hline Disease duration at inclusion, years (mean \pm SD) & $16.07 \pm 8.1$ \\
\hline Female gender & $260(45.7 \%)$ \\
\hline IBD subtype & \\
\hline - Ulcerative colitis & $458(80.4 \%)$ \\
\hline - CD & $102(17.9 \%)$ \\
\hline - Indeterminate & $9(1.6 \%)$ \\
\hline Extensive colitis & $213(46.6 \%)$ \\
\hline Boston >6 & $663(93.5 \%)$ \\
\hline Pseudopolyps & $200(34.6 \%)$ \\
\hline Mucosal healing (Mayo 0 - 1) & $623(87.9 \%)$ \\
\hline Deep remission (histological healing) & $339(64.2 \%)$ \\
\hline
\end{tabular}

All values are $\mathrm{n}(\%)$ except stated otherwise.

IBD, irritable bowel disease; CD, Crohn's disease.

- Table 2 Descriptive endoscopic data.

\begin{tabular}{|c|c|c|c|}
\hline & & Frequency & Percentage (\%) \\
\hline \multirow[t]{6}{*}{ Paris } & Ila & 223 & 11.2 \\
\hline & IIa-c & 2 & 0.1 \\
\hline & IIb & 373 & 18.7 \\
\hline & IIC & 4 & 0.2 \\
\hline & Ip & 145 & 7.3 \\
\hline & Is & 526 & 26.3 \\
\hline \multicolumn{2}{|l|}{ TOTAL } & 1998 & 100 \\
\hline \multirow{5}{*}{$\begin{array}{l}\text { Pit } \\
\text { pattern }\end{array}$} & 1 & 701 & 35.1 \\
\hline & II & 494 & 24.7 \\
\hline & IIIL & 105 & 5.3 \\
\hline & IIIs & 92 & 4.6 \\
\hline & IV & 21 & 1.1 \\
\hline \multicolumn{2}{|l|}{ TOTAL } & 1998 & 100 \\
\hline \multirow{6}{*}{$\begin{array}{l}\text { Locali- } \\
\text { zation }\end{array}$} & Cecum & 4 & 0.2 \\
\hline & Right colon & 261 & 12.9 \\
\hline & Transversum colon & 216 & 10.7 \\
\hline & Descending colon & 623 & 30.8 \\
\hline & Sigmoid colon & 550 & 27.2 \\
\hline & Rectum & 332 & 16.4 \\
\hline TOTAL & & 2025 & 100 \\
\hline
\end{tabular}


Table 3 Histological analysis of lesions found on chromoendoscopy.

\begin{tabular}{|c|c|c|c|c|c|}
\hline \multicolumn{5}{|l|}{ Histological analysis } & \multirow{2}{*}{$\begin{array}{l}\text { Total } \\
2025(100 \%) \\
1793(88.5 \%)\end{array}$} \\
\hline Non-Neoplastic lesions & $\begin{array}{l}\text { Normal } \\
(43.9 \%) \\
788\end{array}$ & $\begin{array}{l}\text { Hyperplastic } \\
(35.9 \%) \\
645\end{array}$ & $\begin{array}{l}\text { Inflammatory } \\
(13.1 \%) \\
235\end{array}$ & $\begin{array}{l}\text { Other } \\
7 \% \\
125\end{array}$ & \\
\hline Neoplastic lesions & $\begin{array}{l}\text { LGD } \\
223(96.1 \%)\end{array}$ & $\begin{array}{l}\text { HGD } \\
8(3.4 \%)\end{array}$ & $\begin{array}{l}\text { CRC } \\
1(0.5 \%)\end{array}$ & & $232(11.5 \%)$ \\
\hline
\end{tabular}

- Table4 Univariate analysis.

\begin{tabular}{|l|l|l|}
\hline & P value & OR \\
\hline Sex & 0.479 & \\
\hline Sex (male) & 0.803 & 1.196 \\
\hline Sex (female) & 0.226 & 1.378 \\
\hline Extensive colitis (E3) & 0399 & 0.783 \\
\hline Pseudopolyps & 0.131 & 2.380 \\
\hline No Pseudopolyps & & \\
\hline Endoscopic activity & 0.107 & \\
\hline Endoscopic activity & 0.035 & 3.306 \\
\hline No endoscopic activity & 0.549 & 1.211 \\
\hline Paris & 0.000 & \\
\hline Paris Ila & 0.011 & 0.018 \\
\hline Paris Ila-c & 0.055 & 0.049 \\
\hline Paris Ilb & 1.000 & $3.215 \mathrm{E}+9$ \\
\hline Paris Ilc & 0.010 & 0.016 \\
\hline Paris Is & 0.005 & 0.009 \\
\hline Paris Ip & 0.091 & 0.072 \\
\hline Location & 0.001 & \\
\hline Cecum & 0.917 & 1.131 \\
\hline Right colon & 0.052 & 2.562 \\
\hline Transversum colon & 1.000 & 0.000 \\
\hline Descending colon & 0.655 & 0.812 \\
\hline Sigmoid colon & 0.236 & 0.521 \\
\hline Rectum & 0.123 & 0.465 \\
\hline Type of IBD & & \\
\hline Ulcerative colitis & & \\
\hline Crohn's disease & & \\
\hline Inderminate colitis & & \\
\hline
\end{tabular}

- Table 5 Multivariate analysis.

\begin{tabular}{|l|l|l|l|}
\hline & $\mathbf{P}$ value & OR & IC95\% \\
\hline Endoscopic activity & $\mathbf{0 . 0 0 1}$ & $\mathbf{2 . 6 9 2}$ & $\mathbf{1 . 4 7 4 - 4 . 9 1 6}$ \\
\hline Paris 0lla & 0.153 & 1.460 & $0.869-2.450$ \\
\hline Paris 0lla-c & 1.000 & $3.536 \mathrm{E}+10$ & - \\
\hline Paris 0llb & 0.712 & 0.910 & $0.550-1.505$ \\
\hline Paris 0llc & 0.999 & 0.000 & $0.000-$ \\
\hline Paris 0ls & $\mathbf{0 . 0 0 0}$ & $\mathbf{2 . 7 5 1}$ & $\mathbf{1 . 8 8 1 - 4 . 0 2 3}$ \\
\hline Paris 0lp & 0.010 & 7.260 & $1.597-33.004$ \\
\hline Cecum & 0.260 & 2.022 & $0.595-6.875$ \\
\hline Right colon & $\mathbf{0 . 0 0 6}$ & $\mathbf{2 . 0 3 3}$ & $\mathbf{1 . 2 2 5}-\mathbf{3 . 3 7 3}$ \\
\hline Transversum colon & 0.084 & 5.971 & $0.785-45.441$ \\
\hline Descending colon & 0.601 & 0.878 & $0.540-1.429$ \\
\hline Sigmoid colon & $\mathbf{0 . 0 0 4}$ & $\mathbf{0 . 4 4 5}$ & $\mathbf{0 . 2 5 5} \mathbf{0 . 7 7 5}$ \\
\hline Rectum & $\mathbf{0 . 0 0 6}$ & $\mathbf{0 . 4 2 1}$ & $\mathbf{0 . 2 2 8}-\mathbf{0 . 7 7 9}$ \\
\hline
\end{tabular}

omy with an ileorectal anastomosis. Concerning non-targeted biopsies, neither perilesional samples nor random samples obtained to assess inflammatory activity showed dysplasia.

Dysplastic lesions, compared to non-dysplastic lesions, were more frequently localized in the right colon (OR 2.033; $95 \% \mathrm{CI}$ 1.225-3.373; $P=0.006$ ) in our univariate and multivariate analysis ( $\triangleright$ Table 4, $\triangleright$ Table 5). However, lesions localized in the rectum (OR 0.421 ; $95 \% \mathrm{Cl} 0.228-0.779 ; P=0.006$ ) or sigmoid coIon (OR 0.445; $95 \% \mathrm{Cl} 0.255-0.775 ; P=0.004$ ) were protective factors for dysplasia. Endoscopic activity during chromoendoscopy was an independent risk factor for dysplasia detection (OR 2.692; 95\% CI 1.474-4.916; $P=0.001)$. Gender, type of IBD (UC/CD), and extension of disease were not associated with dysplastic findings.

Regarding lesion type and size, sessile polyp (Paris 0-Is) (OR $2.751 ; 95 \% \mathrm{Cl} 1.881-4.023 ; P=0.000)$ was a risk factor for dysplastic lesions. Size $>1 \mathrm{~cm}$, flat elevated lesions (Paris Ila), flat lesions (Paris Ilb), and presence of pseudopolyps were not associated with dysplastic findings.

Taking the Kudo pit pattern as the gold standard for dysplasia detection, endoscopists correctly classified 72/232 neoplastic lesions as Kudo pit pattern $\geq$ III and 1660/1793 non-neoplas- 
- Table 6 Correlation between Kudo pit pattern $\geq$ III and dysplasia.

\begin{tabular}{|l|l|l|l|}
\hline Sensitivity & Specificity & PPV & NPV \\
\hline $36 \%$ & $94 \%$ & $41 \%$ & $92 \%$ \\
\hline
\end{tabular}

Area under the curve 0.649

PPV, positive predictive value; NPV, negative predictive value.

- Table 7 Comparison of first and last 50 chromoendoscopies regarding accuracy for detecting dysplastic and non-dysplastic lesions.

\begin{tabular}{|l|l|l|l|}
\hline \multicolumn{2}{|l|}{ First $\mathbf{5 0}$ chromoendoscopies } \\
\hline Sensitivity & Specificity & PPV & NPV \\
\hline $58 \%$ & $84 \%$ & $31 \%$ & $94 \%$ \\
\hline Area under the curve 0.71 & & \\
\hline Last 50 chromoendoscopies & & \\
\hline Sensitivity & Specificity & PPV & NPV \\
\hline $33 \%$ & $99 \%$ & $86 \%$ \\
\hline Area under the curve 0.661 & & \\
\hline PPV, positive predictive value; NPV, negative predictive value \\
\hline
\end{tabular}

tic lesions as Kudo pit pattern <III. Thus, sensitivity, specificity, PPV and NPV for dysplasia optical diagnosis were 36\%, 94\%, $41 \%$, and $92 \%$ respectively. Global accuracy value for onsite optical diagnosis was $87 \%$ ( $>$ Table 6 , $\triangleright$ Fig. 2 )

To assess the effect of the learning curve on the correlation between Kudo pit pattern and dysplasia detection, we compared the first 50 colonoscopies with the last 50 colonoscopies performed at the most experienced center, and observed a trend towards better accuracy, maintaining the high NPV from the beginning of the study period ( $\vee$ Table 7, $\triangleright$ Fig. 3, $\triangleright$ Fig.4)

\section{Discussion}

Patients with longstanding IBD have a higher risk for CRC, with an incidence of 1.21 per 1000 patient-years in studies published in the last decade [2]. According to a 1992 study [14], guidelines recommended obtaining at least 34 random biopsies from all segments of the colon to detect dysplasia, with a probability of $90 \%$. Currently, with newer endoscopic technologies, dysplasia is identifiable [15] and most clinical and endoscopic guidelines $[3,16,17]$ recommend chromoendoscopy rather than high-definition white-light endoscopy (WLE) or narrow-band imaging for surveillance in IBD longstanding patients with a high evidence level (1B) and a recommendation grade of B. In 2011, a meta-analysis [18] including 1277 patients from six prospective cross-sectional trials showed clear differences in the proportion of dysplastic lesions identified by targeted biopsy between chromoendoscopy and standard WLE. In this meta-analysis, this difference was maintained when we analyzed only flat lesions, with a two to three-fold increase in dysplasia detection per patient and a four- to five-fold increase per lesion. Thus, the difference in yield of dysplasia between chro-

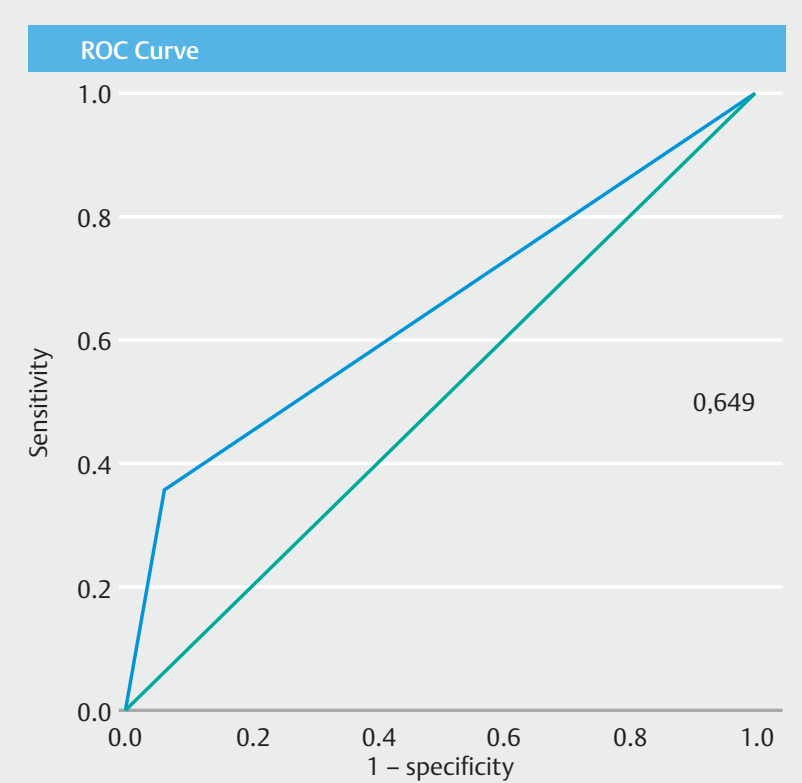

Diagonal segments are produced by ties.

- Fig. 2 Correlation between Kudo pit pattern and histological analysis.

\section{ROC Curve}

1.0

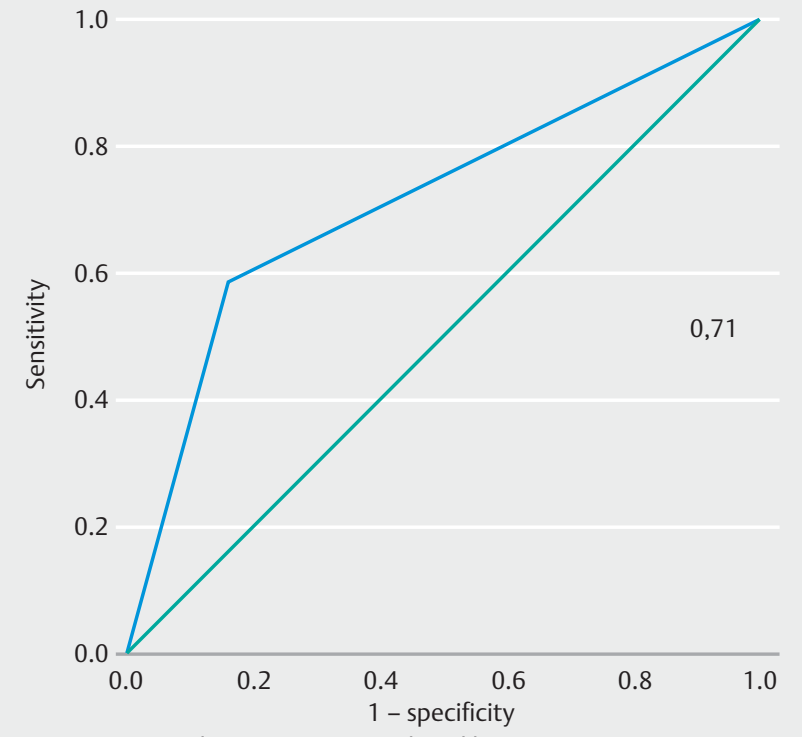

Diagonal segments are produced by ties.

- Fig. 3 Correlation between Kudo pit pattern and histological analysis in the first 50 chromoendoscopies at the most experience center.

moendoscopy and WLE was $7 \%(95 \% \mathrm{Cl} 3.2-11.3)$ on a per-patient analysis with a number necessary to treat of 14.3 . The difference in proportion of lesions detected by targeted biopsies was $44 \%(95 \% \mathrm{Cl} 28.6-59.1)$, and flat lesions were $27 \%$ (95\% Cl 11.2-41.9) in favor of chromoendoscopy. With respect to clinical trials, a Spanish multicenter prospective cohort study 


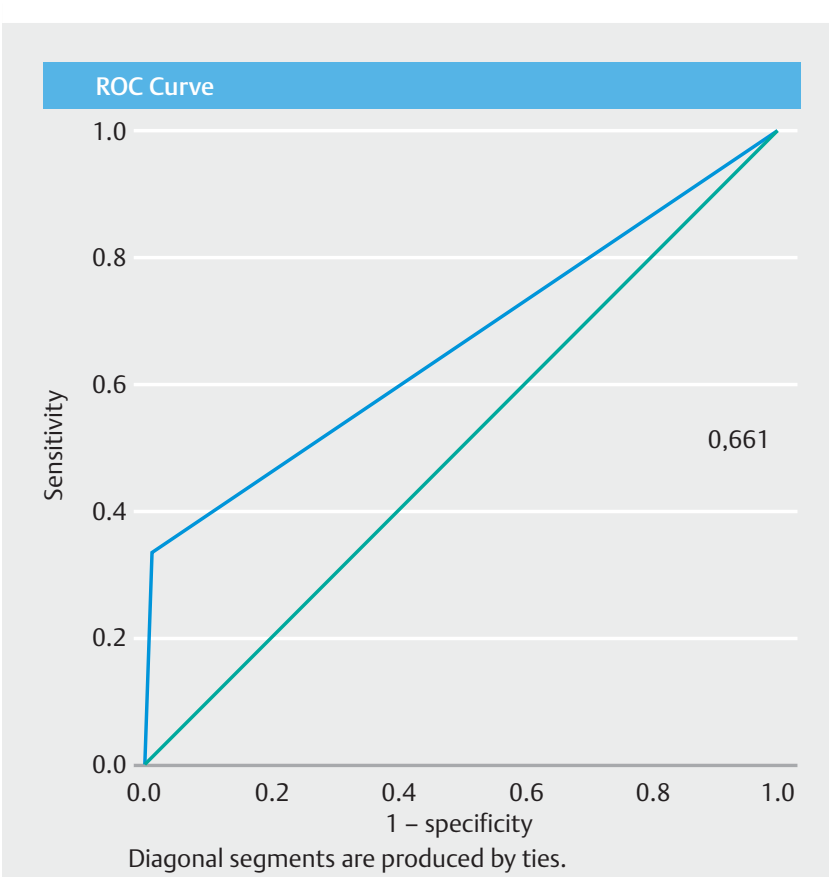

- Fig. 4 Correlation between Kudo pit pattern and histological analysis in the last 50 chromoendoscopies.

[8] demonstrated a considerable increase in dysplasia detection rate with chromoendoscopy-targeted biopsies compared with white light-targeted biopsies. A recently published paper with a different methodology (1:1 randomized trial) did not show any difference in detecting dysplasia when comparing narrowband imaging and chromoendoscopy [19].

To date, and although the main limitation of our study is retrospective methodology, this is the largest published series of chromoendoscopy and dysplasia detection in real life. Previously, Marion et al [20] evaluated 68 patients with ulcerative colitis in a 5-year period using random biopsy, WLE, and chromoendoscopy and detected 27 of 44 dysplastic lesions by chromoendoscopy. Gasia et al [21] detected a total of 243 lesions in a cohort of 454 IBD patients who underwent surveillance between 2011 and 2014. Moreover, a prospective multicenter trial in Spain [8] confirmed the value of dye-based chromoendoscopy in 350 IBD patients undergoing surveillance colonoscopy under real-life conditions with white-light colonoscopy assessment followed by indigo carmine chromoendoscopy examination in a segmental fashion. The results of this last study showed a $57 \%$ incremental yield for IBD-associated neoplasia using dyebased chromoendoscopy vs white-light colonoscopy, with a dysplasia rate of $15.7 \%$ (1 CRC, 5 HGD, 88 LGD).

The current study, a multicenter cohort that included 709 chromoendoscopies of 569 consecutive patients in a real-life setting, reported a dysplasia detection rate of $11.5 \%$ via targeted chromoendoscopic biopsies in patients with longstanding $\mathrm{IBD}$, dysplasia not being detected in any perilesional biopsy, nor in polyps (Paris 0-Is/Paris 0lp) nor in any other type of slightly elevated (Paris 0 -Ila) or flat (Paris 0 -IIb-c) resected lesion. Such findings support the conclusions of several articles, the most recent one published by Lahiff et al [22], where a low efficacy was found after analyzing the probability of detecting dysplasia "polyp-adjacent" biopsies in IBD patients by using high-definition endoscopes and techniques such as chromoendoscopy. Neither did we find dysplasia in random biopsies by colonic segment, despite the fact that the purpose of this study with random biopsies was to analyze histological healing and not presence of invisible dysplasia; practice which remains controversial.

Pseudopolyps were present in one-third of our chromoendoscopies and contrary to the literature, they were not associated with presence of dysplasia. However, and according to data published to date, lesions localized to the proximal colon (right or transverse colon) and elevated lesions (Paris 0-Is) are risk factors for dysplasia [19]. Pseudopolyps were described as a risk factor for a higher incidence of CRC (OR 2.1), although other risk factors such as stenosis (OR 5.7) or primary sclerosing cholangitis (OR 4.8) demonstrated a higher risk [3]. To date, without narrow-band imaging or dye use, it is difficult to differentiate an inflammatory pseudopolyp from a dysplastic polyp, which could lead to overestimation of CRC risk in the presence of pseudopolyps. However, pseudopolyps are a consequence of severe colonic inflammation, which is another risk factor for higher CRC incidence. Thus, results of other studies that employ chromoendoscopy will be required to confirm our results.

Degree of inflammation is currently an established risk factor for CRC. In a cohort of 418 patients with ulcerative colitis [23] who were followed for a median of 6.7 years and received an average of 5 surveillance colonoscopies at a median interval of 0.8 years, 15 patients progressed to advanced neoplasia (HGD or CRC), while 65 progressed to any neoplasia (LGD, $H G D$, or $(R C)$. A significant relationship was found between the degree of inflammation and progression to advanced neoplasia, with a unit increase in the mean inflammation score associated with a three-fold increase in risk of advanced neoplasia. In our study, endoscopic activity during chromoendoscopy was an independent risk factor for dysplasia detection.

Regarding lesion size and morphology, we identified more dysplastic findings in Paris 0-Is or 0-Isp lesions. In a 2007 meta-analysis [24], dysplasia progression to CRC was 14 per 1000 person-years (95\% Cl: $5.0-34$ ) and incidence of any advanced lesion was 30 per 1000 person-years (95\% Cl: $12-76)$. Other studies on natural history of LGD published since the 2007 review have reported progression rates ranging from $4.9 \%$ to $30 \%[25,26]$. When analyzing only polypoid lesions, this risk seems to be much lower (0.9\%) [27]. Only two studies describe long-term progression when dysplastic lesions are identified by chromoendoscopy and reported controversial results because they employed notably different methodologies $[20,28]$. It will be interesting if the polypoid dysplastic lesions found in chromoendoscopy in our IBD population have the same risk for CRC as flat lesions (Paris 0 -IIb) or flat elevated lesions (Paris 0 -Ila) in the long term. We did not find any other risk or protective factor for dysplasia with regard to sex, gender, extensive colitis, or lesion size. 
Identification of Kudo pit pattern is challenging in IBD patients and en bloc removal of all lesions is recommended. Moreover, because of chronic inflammation, endoscopic management of dysplasia is associated with a higher rate of complications [29]. Thus, if we were able to correctly identify lesions without dysplasia, we could leave them onsite without endoscopic complications, reducing procedure time. Overall, we reported very low rates of sensitivity and PPV compared with reports from other European groups [30]. However, we had similar and high percentages of specificity and NPV when high-definition endoscopes without optical magnification were used [31], and even with endoscopes with optical magnification where sensitivity percentages are clearly higher without losing high NPV percentages [32]. This means that during endoscopy, when the endoscopist describes a lesion with a high probability of dysplasia (Kudo>III), probability of correlation with histological findings is low since many lesions do not have dysplasia. However, when a lesion with low probability of dysplasia (Kudo I or II) is described, probability of correlation with histological findings is very high. In a screening technique, it is important to correctly identify disease (in this case, dysplastic lesions), and high NPV indicates that these techniques are valuable for exclusion of dysplasia.

It is also important to ascertain if training affects outcomes because much of the existing chromoendoscopic data, especially data demonstrating positive results, come from centers where gastroenterologists have particular expertise in chromoendoscopy. Although Mooiweer et al [33] concluded that a lower neoplasia detection rate could be due to endoscopist inexperience, Carvallal et al [8] reported no statistical differences in dysplasia detection when comparing expert (>20 chromoendoscopies) and non-expert endoscopists. In our study, all the endoscopists commenced performing chromoendoscopy after systematic training, standardization of the operative procedure, and partnered learning. However, not all the endoscopists were experts as, with time, they learned by performing their own chromoendoscopies at their hospitals. We compared the first 50 chromoendoscopies with the last 50 chromoendoscopies at the center with the most experience (more than 20 chromoendoscopies done previously) and observed that the NPV remained high, while the PPV improved. Thus, the endoscopists were able to detect non-neoplastic lesions from the outset, improving the correlation between Kudo III and dysplastic lesions with experience.

According to these results, this high NPV and left colon location could prevent removal of all identified lesions, at least, in the sigmoid colon and rectum because of the very low probability of dysplasia, with regard to Kudo I or II pit pattern. These results are important for two reasons. First, if low-probability dysplastic lesions are not removed, procedure duration, which is a major problem with chromoendoscopy, will decrease. Second, in asymptomatic patients, large and numerous Kudo I or II pit pattern lesions are observed, mostly in the sigmoid colon and rectum. If these are removed, complications such as bleeding or even perforation may occur, even when some of these lesions may eventually be found to be non-dysplastic. Nevertheless, Kudo pit pattern II lesions could have a different meaning because most of them correspond to hyperplastic lesions in histology, and could be serrated lesions, which have a potential for neoplasia.

\section{Conclusion}

In conclusion, our results confirmed the efficacy of chromoendoscopy for dysplasia detection, with a dysplasia yield of $11.5 \%$, in a real-life screening study. Although in our study, the Kudo pit pattern was not an accurate diagnostic method for predicting dysplastic lesions, the high NPV and the protective influence of left colonic lesions for dysplastic findings could prevent removal of lesions with Kudo pit pattern I and, perhaps, Kudo pit pattern II in the rectum or sigmoid colon because they have a markedly low probability of dysplasia; thus, improving procedure time and avoiding endoscopic complications. STROBE guidelines were used for elaboration of this article, using the checklist of each one of the points of the methodology specified to guarantee the best communication of this observational study [34].

\section{Acknowledgements}

The authors thank Dr. Antonio Rodriguez, head of the department of Gastroenterology and Hepatology in Salamanca Hospital, for both the foundation of our IBD group in Castilla y León (GEICYL) and his support and dedication to the IBD patients as well as development of this paper

\section{Competing interests}

None

\section{References}

[1] Jess T, Gamborg M, Matzen P et al. Increased risk of intestinal cancer in Crohn's disease: a meta-analysis of population-based cohort studies. Am J Gastroenterol 2005; 100: 2724-2729

[2] Castaño-Milla C, Chaparro M, Gisbert JP. Systematic review with meta-analysis: the declining risk of colorectal cancer in ulcerative colitis. Aliment Pharmacol Ther 2014; 39: 645-659

[3] Magro F, Gionchetti P, Eliakim R et al. European Crohn's and Colitis Organisation. Third European Evidence-based Consensus on Diagnosis and Management of Ulcerative Colitis. Part 1: Definitions, Diagnosis, Extra-intestinal Manifestations, Pregnancy, Cancer Surveillance, Surgery, and Ileo-anal Pouch Disorders. J Crohn Colitis 2017; 11: $649-670$

[4] Loftus EV Jr. Does monitoring prevent cancer in inflammatory bowel disease? J Clin Gastroenterol 2003; 36: (Suppl. 05): S79-83; discussion $594-96$

[5] Collins PD, Mpofu C, Watson AJ et al. Strategies for detecting colon cancer and/or dysplasia in patients with inflammatory bowel disease. Cochrane Database Syst Rev 2006: CD000279

[6] Laine L, Kaltenbach T, Barkun A et al. for the SCENIC Guideline Development Panel SCENIC International Consensus Statement on Surveillance and Management of Dysplasia in Inflammatory Bowel Disease. Gastroenterology 2015; 148: 639-645 
[7] Kudo S, Rubio CA, Teixeira CR et al. Pit Pattern in colorectal neoplasia: Endoscopic magnifying view. Endoscopy 2001; 33: 367-373

[8] Carballal S, Maisterra S, López-Serrano A et al. EndoCAR group of the Spanish Gastroenterological Association and Spanish Digestive Endoscopy Society. Real-life chromoendoscopy for neoplasia detection and characterisation in long-standing IBD. Gut 2018; 67: 70 - 78

[9] Lai E], Calderwood AH, Doros G et al. The Boston bowel preparation scale: a valid and reliable instrument for colonoscopy-oriented research. Gastrointest Endosc 2009; 69: 620-625

[10] Schroeder KW, Tremaine WJ, Ilstrup DM. Coated oral 5-aminosalicylic acid therapy for mildly to moderately active ulcerative colitis. A randomized study. N Engl J Med 1987; 317: 1625 -1629

[11] Daperno M, D'Haens G, Van Assche G et al. Development and validation of a new, simplified endoscopic activity score for Crohn's disease: the SES-CD. Gastrointest Endosc 2004; 60: 505- 512

[12] Kieslich R, Neurath MF. Surveillance colonoscopy in ulcerative colitis: magnifying chromoendoscopy in the spotlight. Gut 2004; 53: 165 167

[13] Sanduleanu S, Kaltenbach T, Barkun A et al. A roadmap to the implementation of chromoendoscopy in inflammatory bowel disease colonoscopy surveillance practice. Gastrointest Endosc 2016; 83: 213 222

[14] Rubin CE, Haggitt RC, Burmer GC et al. DNA aneuploidy in colonic biopsies predicts future development of dysplasia in ulcerative colitis. Gastroenterology 1992; 103: 1611-1620

[15] Van der Broek FJ, Stokkers PC, Reitsma JB et al. Random biopsies taken during colonoscopy surveillance of patients with longstanding ulcerative colitis: low yield and absence of clinical consequences. Am J Gastroenterol 2014; 109: 715-722

[16] Arraye FA, Odze RD, Eaden J et al. AGA Institute Medical Position Panel on Diagnosis and Management of Colorectal Neoplasia in Inflammatory Bowel Disease. AGA medical position statement on the diagnosis and management of colorectal neoplasia in inflammatory bowel disease. Gastroenterology 2010; 138: $738-745$

[17] Shergill AK, Lightdale JR, Bruining DH. American Society for Gastrointestinal Endoscopy Standards of Practice The role of endoscopy in inflammatory bowel disease. Gastrointest Endosc 2015; 81: 1101 1121

[18] Subramanian V, Mannath J, Ragunath K et al. Metaanalysis: the diagnostic yield of chromoendoscopy for detecting dysplasia in patients with colonic inflammatory bowel disease. Aliment Pharmacol 2011; 33: $304-312$

[19] lacucci M, Kaplan GG, Panaccione R et al. A randomized trial comparing high definition colonoscopy alone with high definition dye spraying and electronic virtual chromoendoscopy for detection of colonic neoplastic lesions during IBD surveillance colonoscopy. Am J Gastroenterol 2018; 113: 225-234

[20] Marion JF, Waye JD, Israel Y et al. Chromoendoscopy Study Group at Mount Sinai School of Medicine. Chromoendoscopy is more effective than standard colonoscopy in detecting dysplasia during long-term surveillance of patients with colitis. Clin Gastroenterol Hepatol 2016; 14: $713-719$
[21] Gasia MF, Ghosh S, Panaccione R et al. Targeted biopsies identify larger proportions of patients with colonic neoplasia undergoing highdefinition colonoscopy, dye chromoendoscopy, or electronic virtual chromoendoscopy. Clin Gastroenterol Hepatol 2016; 14: 704-712. e4

[22] Lahiff C, Mun Wang L, Travis SPL et al. Diagnostic yield of dysplasia in polyp-adjacent biopsies in patients with inflammatory bowel disease: A cross sectional study. J Crohns Colitis 2018; 12: 670-676

[23] Gupta RB, Harpaz N, Itzkowitz S et al. Histologic inflammation is a risk factor for progression to colorectal neoplasia in ulcerative colitis: a cohort study. Gastroenterology 2007; 133: 1099-1105

[24] Thomas T, Abrams HA, Robinson RJ et al. Meta-analysis: cancer risk of low-grade dysplasia in chronic ulcerative colitis. Aliment Pharmacol Ther 2007; 25: 657-668

[25] Navaneethan U, Jegadeesan R, Gutierrez NG et al. Progression of lowgrade dysplasia to advanced neoplasia based on the location and morphology of dysplasia in ulcerative colitis patients with extensive colitis under colonoscopic surveillance. J Crohns Colitis 2013; 7: e684-691

[26] Choi CH, Ignjatovic-Wilson A, Askari A et al. Low-grade dysplasia in ulcerative colitis: risk factors for developing high-grade dysplasia or colorectal cancer. Am J Gastroenterol 2015; 110: 1461 - 1471

[27] Wanders LK, Dekker E, Pullens B et al. Cancer risk after resection of polypoid dysplasia in patients with long-standing ulcerative colitis: a meta-analysis. Clin Gastroenterol Hepatol 2014; 12: 756 - 764

[28] Ten Hove JR, Mooiweer E, Van der Meulen de Jong AE et al. Clinical implications of low grade dysplasia found during inflammatory bowel disease surveillance: a retrospective study comparing chromoendoscopy and white-light endoscopy. Endoscopy 2017; 49: 161-168

[29] Tharian B, George N, Navaneethan U. Endoscopy in the diagnosis and management of complications of inflammatory bowel disease. Inflamm Bowel Dis 2016; 22: $1184-1197$

[30] Kiesslich R, Fritsch J, Holtmann M et al. Methylene blue-aided chromoendoscopy for the detection of intraepithelial neoplasia and colon cancer in ulcerative colitis. Gastroenterology 2003; 124: 880-888

[31] Bisschops R, Bessissow T, Dekker E et al. Pit pattern analysis with highdefinition chromoendoscopy and narrow band imaging for optical diagnosis of dysplasia in patients with ulcerative colitis. Gastrointest Endosc 2017; 86: 1100-1106

[32] Vleugels JL, Rutter M, Ragunath K et al. Diagnostic accuracy of endoscopic trimodal imaging and chromoendoscopy for lesion characterisation in ulcerative colitis surveillance - ETMI or chromoendoscopy for lesion characterisation in colitis. J Crohns Colitis 2018; 12: 1438 1447

[33] Mooiweer E, van der Meulen-de Jong AE, Ponsioen CY et al. Chromoendoscopy for surveillance in inflammatory bowel disease does not increase neoplasia detection compared with conventional colonoscopy with random biopsies: results from a large retrospective study. Am J Gastroenterol 2015; 110: 1014-1021

[34] von Elm E, Altman DG, Egger M et al. for the STROBE initiative. Strengthening the Reporting of Observational Studies in Epidemiology (STROBE) statement: guidelines for reporting observational studies. BMJ 2007; 335: 806-808 